\title{
Época de nascimento sobre a composição regional e tecidual da carcaça de cordeiros da raça Texel
}

\section{Gilson de Mendonça $a^{1,2}$, José Carlos da Silveira Osório 2, 3, Maria Teresa Moreira Osório³, Isabella Dias Barbosa Silveira ${ }^{4}$, Michelle Gonçalves ${ }^{5}$, Anilza Rocha ${ }^{5}$}

\author{
${ }^{1}$ Faculdade de Zootecnia - UNIPAMPA. \\ 2 Bolsista do CNPq. \\ ${ }^{3}$ Departamento de Zootecnia, UFPEL. \\ ${ }^{4}$ Bolsista PRODOC CAPES - UFPEL. \\ ${ }^{5}$ Curso de Graduação em Medicina Veterinária - UFPEL.
}

RESUMO - Foram avaliados os efeitos de épocas alternativas de nascimento sobre a composição regional e tecidual da carcaça em ovinos. Quarenta e nove cordeiros machos não-castrados da raça Texel, nascidos em duas épocas (agosto e novembro), foram mantidos em regime de pastagem e abatidos com média de idade de 129 e 164 dias, respectivamente. Previamente aos abates foi feita a avaliação da produção forrageira do campo pelo método Botanal. Foram verificadas melhores condições forrageiras para os cordeiros nascidos em agosto, que apresentaram maior peso e proporção na maioria dos cortes, assim como menor proporção de músculo na paleta e perna; apresentando maior conteúdo de tecido adiposo na maioria dos cortes da carcaça. Para os cordeiros nascidos em novembro, ocorreu maior relação músculo:gordura e músculo:osso na paleta e na perna, assim como maior relação músculo:gordura no costilhar. As condições nutricionais são responsáveis pelas diferenças nos pesos e rendimentos dos cortes, assim como na composição tecidual da carcaça, em cordeiros mantidos em regime de pasto, viabilizando o uso de época alternativa de nascimentos para incrementar a oferta de animais para o abate.

Palavras-chave: carne, ovinos, cortes

\section{Birth season on regional and tissue carcass composition in Texel breed lambs}

\begin{abstract}
The effect of alternative birth season on regional and tissue carcass composition of sheep was evaluated. Forty nine (49) Texel intact male lambs, born in two seasons (August and November), were kept under grazing and slaughtered with an average age of 129 and 164 days, respectively. Prior to slaughter forage production was measured using Botanal method. Lambs born in August had more favorable forage conditions, showing higher body weight and proportion in the majority of cuts, as well as lower proportion of shoulder and leg muscles showing higher adipose tissue content in the majority of carcass cuts. For lambs born in November, a higher muscle:fat and muscle:bone rate in shoulder and leg, as well as a higher ribcut muscle:fat rate. Nutritional conditions are responsible for differences in weights and cuts yields, as well as for the tissue carcass composition, in lambs maintained under grazing regime, making feasible the use of alternative birth periods to increase animal offer for slaughter.
\end{abstract}

Key Words: cuts, meat, sheep

\section{Introdução}

No Rio Grande do Sul, a estacionalidade reprodutiva característica da espécie ovina -, aliada às condições de meio ambiente existentes na região, determina uma única época de nascimentos no estado e, conseqüentemente, limitação no período de oferta de cordeiros para o abate ao longo do ano.

A categoria de ovinos com maior aceitabilidade no mercado consumidor é o cordeiro, pela melhor qualidade da carne, maior rendimento e maior eficiência produtiva, devido à alta velocidade de crescimento (Pilar et al., 2005).

A superioridade na quantidade de músculo em cordeiros da raça Texel, ou oriundos do cruzamento com esta raça, com maior quantidade desse tecido principalmente na perna, é descrita por vários autores (Silva Sobrinho, 1999; Costa et al., 1999; Garibotto et al., 1999). Destaca-se também nesta raça a aptidão para produção de carne magra, com melhores relações músculo/osso (Purchas et al., 2002). 
Embora as carcaças possam ser comercializadas inteiras, o uso de cortes comerciais proporciona a obtenção de preços diferenciados, além de permitir aproveitamento mais racional com mínimo de desperdício (Silva Sobrinho \& Silva, 2000).

A modificação na idade de abate dos cordeiros pode determinar alterações na composição tecidual nos cortes da carcaça. Osório et al. (2000), trabalhando com cordeiros de quatro raças (Ideal, Corriedale, Romney Marsh e Texel), verificaram que, excetuando-se a raça Ideal, nas demais houve incremento na gordura da perna e diminuição do percentual de músculo nesta região, com o aumento da idade. Goliomytis et al. (2006) observaram que o percentual de músculo e ossos diminuiu com o aumento da idade, enquanto o percentual de gordura sofreu forte incremento. Santos et al. (2001), trabalhando com cordeiros machos não-castrados da raça Santa Inês, verificaram que, com o avanço da idade, houve comprometimento na qualidade dos cortes.

Considerando-se uma mesma raça, ao aumentar o peso de carcaça, diminui-se a proporção de osso e eleva-se a de gordura, enquanto o tecido muscular mantém-se constante, ou seja, a carcaça fica proporcionalmente mais gorda (Osório et al., 2000, 2002b).

Objetivou-se com este trabalho verificar a viabilidade de épocas alternativas de nascimento sobre a composição regional e tecidual das carcaças, em cordeiros da raça Texel.

\section{Material e Métodos}

O experimento, em sua fase de campo, foi desenvolvido em uma propriedade particular no município de Santa Vitória do Palmar, no estado do Rio Grande do Sul, localizada entre os paralelos $32^{\circ} 32^{\prime} 00^{\prime \prime}$ norte e $33^{\circ} 45^{\prime} 00^{\prime \prime}$ sul. O clima predominante na região é o subtropical com estações bem definidas e chuvas regulares distribuídas ao longo do ano, totalizando uma precipitação anual média de $1.200 \mathrm{~mm}$, sendo os meses de dezembro e janeiro os mais secos. As temperaturas oscilam entre $-2^{\circ} \mathrm{C}$ e $36^{\circ} \mathrm{C}$, sendo a média de $23^{\circ} \mathrm{C}$, com ocorrência de geadas nos meses de junho, julho e agosto.

Os campos são cobertos por vegetação nativa, apresentando variações qualitativas nos diferentes períodos do ano. Na primavera e no verão, os pastos são baixos e densos, formando uma cobertura natural de boa qualidade para exploração em pastejo. No período de inverno (junho a agosto), não apresentam crescimento e ficam secos pela ocorrência de geadas, ocorrendo, além disso, redução das áreas de campo, em virtude do aumento nos depósitos naturais de água (lagoas e banhados), que são abundantes na região. Agrostologicamente, os campos da região são constituídos por elevado número de espécies rizomatosas e cespitosas de baixo porte, destacando-se as espécies Paspalum notatum (grama boiadeira), Adesmia bicolor (babosa) e Desmodium trifolium (pega-pega) (Mohrdieck, 1993) como as mais comuns.

A fase laboratorial do experimento desenvolveu-se no Laboratório de Carcaças e Carnes, do Departamento de Zootecnia, da Faculdade de Agronomia Eliseu Maciel, na Universidade Federal de Pelotas.

Foram utilizados 49 cordeiros da raça Texel, machos, não-castrados, nascidos de partos simples em duas épocas distintas: agosto $(n=23)$ e novembro $(n=26)$ de 2004 , provenientes de ovelhas acasaladas em março e junho, respectivamente. Os cordeiros foram pesados logo após o nascimento e em intervalos de 28 dias.

Durante a fase de crescimento, os cordeiros permaneceram com suas mães, em campo nativo melhorado, com ocorrência das seguintes espécies de gramíneas e leguminosas exóticas: Lolium multiflorum (azevém), Lotus corniculatus (cornichão) e Trifolium repens (trevo branco). A lotação média durante o período experimental foi de 5 a 6 ovelhas + cordeiros/ha.

Foi feita previamente a cada abate a avaliação da produção forrageira do campo, utilizando-se o método Botanal (Tothill et al., 1992), para se obter a estimativa da produção de matéria seca e composição botânica do campo (Tabela 1).

Para determinação do momento do abate, foi utilizado como critério a condição corporal média do lote, de acordo com metodologia descrita por Osório \& Osório (2005). Na avaliação da condição corporal, foi atribuída nota de 1 a 5 , com escala de 0,5 , em que $1=$ excessivamente magra e 5 = excessivamente gorda. A condição corporal escolhida como

Tabela 1 - Composição botânica (em percentual por espécie) e quantidade de matéria seca $(\mathrm{kg} / \mathrm{ha})$ do campo nativo em cada avaliação

\begin{tabular}{lcrc}
\hline Mês de avaliação & Composição botânica & \multicolumn{1}{c}{$\%$} & MS (kg/ha) \\
\hline Dezembro & Azevém anual & 40,2 & 2.165 \\
& Trevo branco & 15,9 & \\
& Cornichão & 7,5 & \\
& Cynodon dactylon & 16,5 & \\
& Cyperus & 1,2 & \\
& Outras gramíneas & 17,7 & \\
\hline \multirow{2}{*}{ Abril } & Cynodon dactylon & 38,7 & \multirow{2}{*}{1.365} \\
& Piptochaetium & 12,7 & \\
& Setária geniculata & 9,0 & \\
& Oxalis spp & 11,9 & \\
& Outras gramíneas & 18,7 & \\
& Solo descoberto & 10,0 & \\
\hline
\end{tabular}


indicativa do momento para o abate foi de 3,0 e, uma vez atingida, todo o lote foi abatido, após jejum de sólidos e dieta hídrica por período de 14 horas.

Após insensibilização mecânica, os cordeiros foram abatidos por sangria com a seç̧ão das artérias carótidas e veias jugulares. Na seqüência, foram realizadas a esfola, a evisceração e a separação da cabeça e das patas.

Após o abate, as carcaças foram transportadas até o Laboratório de Carcaças e Carnes, do Departamento de Zootecnia, FAEM - UFPEL, onde foram penduradas em câmara fria, permanecendo por 18 horas, sob temperatura média de $1^{\circ} \mathrm{C}$ com ar forçado. Após, foram retiradas da câmara fria e divididas longitudinalmente em duas metades.

Posteriormente, a meia-carcaça foi separada em oito cortes, conforme técnica adaptada de Sánchez \& Sánchez (1988), citados por Cañeque et al. (1989) (Figura 1). Cada corte foi pesado separadamente, calculando-se sua proporção em relação ao peso da meia-carcaça fria. Os cortes obtidos foram: paleta (separada pela seç̧ão dos músculos que a unem à caixa torácica); perna (separada pelo corte entre a última vértebra lombar e primeira sacra); cauda (vértebras coccígeas); lombo com vazio (pelo corte entre a décima terceira vértebra torácica e primeira lombar e sexta lombar e primeira sacra); costelas falsas (pelo corte entre a quinta e sexta vértebras torácicas e entre décima-terceira torácica e primeira lombar); costelas verdadeiras (pelo corte entre a sétima vértebra cervical e primeira torácica e entre a quinta e sexta torácicas); peito (separado pelo corte transversal das costelas, obedecendo linha imaginária desde o apêndice xifóide do esterno até a extremidade inferior da décima costela); e pescoço (obtido pelo corte entre a sétima vértebra cervical e primeira torácica).

Com o somatório dos pesos das costelas verdadeiras, costelas falsas, do peito e lombo com vazio foi obtido o peso do corte, denominado costilhar. Calculou-se a porcentagem de cada corte em relação ao peso da meiacarcaça corrigido (somatório dos pesos de cada corte). Posteriormente, os diferentes cortes obtidos foram congelados para a avaliação tecidual.

Após o congelamento, sucessivamente, a paleta, a perna, as costelas verdadeiras, as costelas falsas e o peito foram submetidos a descongelamento, sendo então pesados e dissecados em seus diferentes componentes teciduais: músculo (musculatura do corte mecanicamente separada de sua base óssea, bem como do conteúdo de gordura intermuscular, gordura subcutânea, fáscias, tendões e grandes vasos); osso (base óssea de cada corte livre de qualquer outro tecido); gordura subcutânea (gordura existente na superfície externa de cada corte, localizada

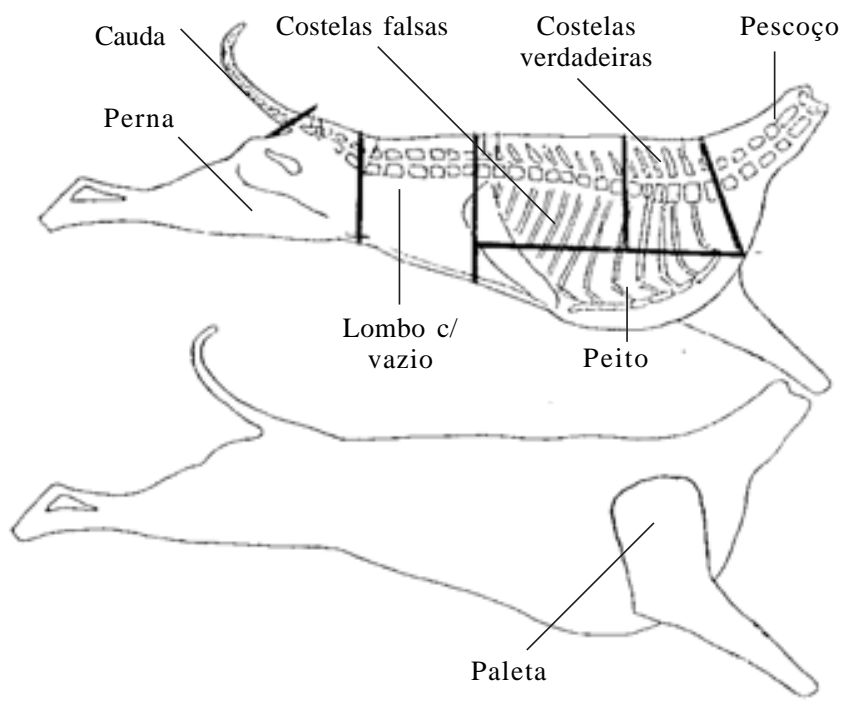

Figura 1 - Esquema da separação anatômica da carcaça.

imediatamente sob a pele); gordura intermuscular (gordura existente entre as massas musculares); e outros tecidos (demais tecidos que não músculos, ossos e gordura, como gânglios, fáscias, tendões e grandes vasos).

Cada tecido que compunha os cortes foi pesado e sua proporção em relação ao respectivo corte, calculada.

Para avaliar o efeito das épocas de nascimento (agosto e novembro) sobre os cortes e a composição tecidual das carcaças, foi utilizado o delineamento experimental completamente casualizado, de modo que cada unidade experimental foi representada pelo cordeiro. $\mathrm{O}$ fator estudado foi a época de nascimento do cordeiro e o modelo estatístico usado na análise de variância foi: $Y_{i j k}=\mu+E_{i}+e_{i j k}$, em que $\mathrm{Y}_{\mathrm{ijk}}=$ observação de produtividade dos cordeiros, $\mu=$ média geral, $\mathrm{E}_{\mathrm{i}}=$ efeito da época de nascimento i do cordeiro $(\mathrm{i}=1,2)$ e $_{\mathrm{ijk}}=$ erro experimental.

\section{Resultados e Discussão}

Cordeiros nascidos em agosto tiveram maiores valores absolutos (kg) na paleta, perna, no pescoço e costilhar, sendo igualmente superiores no peito, lombo com vazio e na cauda, neste caso em valores absolutos e percentuais. Nos animais nascidos em novembro, verificaram-se maiores percentuais na perna e maiores valores nas costelas verdadeiras (kg e \%) (Tabela 2).

Os resultados obtidos já eram esperados, uma vez que, em fase anterior deste mesmo trabalho, os cordeiros nascidos em agosto tiveram maiores pesos de carcaça quente $(17,30 \pm 0,50$ vs $14,40 \pm 0,50, \mathrm{P}<0,001)$ e fria $(16,50 \pm 0,50$ vs 
Tabela 2 - Peso $(\mathrm{kg})$ e rendimentos dos cortes (\%), de acordo com a época de nascimento

\begin{tabular}{lcrrc}
\hline Componente regional & \multicolumn{2}{c}{ Época de nascimento } & \multirow{2}{*}{$\mathrm{P}$} \\
\cline { 3 - 4 } & & \multicolumn{1}{c}{ Agosto } & \multicolumn{1}{c}{ Novembro } & \\
\hline Paleta & $(\mathrm{kg})$ & $1,69 \pm 0,05$ & $1,38 \pm 0,05$ & $* * *$ \\
& $(\%)$ & $20,73 \pm 0,27$ & $20,40 \pm 0,25$ & $\mathrm{~ns}$ \\
Perna & $(\mathrm{kg})$ & $2,81 \pm 0,08$ & $2,43 \pm 0,07$ & $* *$ \\
& $(\%)$ & $34,47 \pm 0,37$ & $35,74 \pm 0,35$ & $*$ \\
Pescoço & $(\mathrm{kg})$ & $0,66 \pm 0,03$ & $0,53 \pm 0,03$ & $* *$ \\
& $(\%)$ & $8,00 \pm 0,30$ & $7,81 \pm 0,28$ & $\mathrm{~ns}$ \\
Costelas & $(\mathrm{kg})$ & $0,48 \pm 0,03$ & $0,57 \pm 0,03$ & $*$ \\
verdadeiras & $(\%)$ & $5,79 \pm 0,26$ & $8,26 \pm 0,24$ & $* * *$ \\
Costelas falsas & $(\mathrm{kg})$ & $0,90 \pm 0,04$ & $0,79 \pm 0,04$ & $\mathrm{~ns}$ \\
& $(\%)$ & $10,90 \pm 0,27$ & $11,54 \pm 0,25$ & $\mathrm{~ns}$ \\
Peito & $(\mathrm{kg})$ & $0,68 \pm 0,02$ & $0,41 \pm 0,02$ & $* * *$ \\
& $(\%)$ & $8,25 \pm 0,019$ & $6,03 \pm 0,18$ & $* * *$ \\
Lombo c/vazio & $(\mathrm{kg})$ & $0,90 \pm 0,04$ & $0,65 \pm 0,04$ & $* * *$ \\
& $(\%)$ & $10,98 \pm 0,36$ & $9,52 \pm 0,34$ & $* *$ \\
Costilhar & $(\mathrm{kg})$ & $2,96 \pm 0,12$ & $2,42 \pm 0,11$ & $* *$ \\
& $(\%)$ & $35,93 \pm 0,51$ & $35,34 \pm 0,48$ & $\mathrm{~ns}$ \\
Cauda & $(\mathrm{kg})$ & $0,07 \pm 0,00$ & $0,05 \pm 0,00$ & $* * *$ \\
& $(\%)$ & $0,87 \pm 0,04$ & $0,72 \pm 0,04$ & $*$ \\
\hline
\end{tabular}

ns $=$ Não-significativo a $5 \%$ pelo teste DMS de Fischer.

$*=\mathrm{P}<0,05 \quad * *=\mathrm{P}<0,01 \quad * * *=\mathrm{P}<0,001$

$13,80 \pm 0,50, \mathrm{P}<0,001)$ que os nascidos em novembro (Mendonça et al., 2007). Quando aumenta o peso da carcaça, elevam-se em valores absolutos os pesos de osso, músculo e gordura e, conseqüentemente, o peso das regiões da carcaça ou cortes comerciais (Osório et al., 2002b).

Garibotto et al. (1999) verificaram pesos superiores para pescoço em cordeiros Texel comparativamente aos deste estudo, ao passo que Roque et al. (1999) obtiveram valores inferiores para este corte em cordeiros da mesma raça. Cano Expósito et al. (2003) encontraram percentuais semelhantes aos observados nete trabalho para paleta, perna e pescoço em cordeiros da raça Segureña, da mesma forma que Gutiérrez et al. (2005), na paleta e perna de cordeiros Pelibuey e suas cruzas. Estes últimos autores, entretanto, encontraram percentuais superiores para pescoço.

Ribeiro et al. (2001) verificaram percentuais semelhantes para perna, inferiores para paleta e superiores para pescoço e costela, em cordeiros Ile de France e Hampshire Down.

As diferenças nas condições nutricionais podem ter sido responsáveis por alterações na composição anatômica das carcaças dos cordeiros, favorecendo aqueles nascidos em agosto. Tonetto et al. (2004), trabalhando com cordeiros Ile de France $\times$ Texel, concluíram que as proporções da costela e perna variam em função do tipo de alimentação a que os animais são submetidos, embora o abate seja com pesos corporais semelhantes. Alves et al.
(2003) verificaram que o efeito do nível energético da dieta sobre o peso da paleta e costela em cordeiros Santa Inês foi linear crescente nesses cortes, com o incremento na energia fornecida na alimentação. Frescura et al. (2005) observaram maior porcentagem de costela e menor de perna em cordeiros mantidos em pastagem cultivada em relação aos confinados, atribuindo a diferença à maior deposição de gordura na costela.

Os cordeiros nascidos em agosto tiveram maiores pesos para osso na paleta, na perna e no peito. Em valores percentuais foram ainda superiores nesse tecido na perna e no peito (Tabela 3 ).

Osório et al. (2002b) citaram que, quando o peso da carcaça aumenta, todos os componentes teciduais elevam-se em valores absolutos. Neste estudo, conforme citado anteriormente, os cordeiros nascidos em agosto apresentaram maiores valores de peso de carcaça, tanto quente quanto fria (Mendonça et al., 2007), e, conseqüentemente, maior peso para o tecido ósseo.

Roque et al. (1999) encontraram pesos inferiores para osso da paleta, em cordeiros Texel, comparativamente aos resultados deste estudo. Costa et al. (1999) e Osório et al. (2000), em cordeiros Texel, e Osório et al. (2002a), em cordeiros cruzas Border Leicester com Corriedale e Ideal, registraram valores semelhantes aos deste trabalho, em kg e \%, para osso da paleta. Pilar et al. (2005) observaram pesos superiores para osso da paleta, porém, em percentuais, os valores foram inferiores. A mesma tendência foi verificada para osso na perna (kg e \%). Ribeiro et al. (2001) descreveram valores próximos aos obtidos neste trabalho para a região da paleta.

No tecido muscular, os cordeiros nascidos em agosto tiveram menor peso de costelas verdadeiras e menor percentual

Tabela 3 - Tecido ósseo (kg e \%), para cada componente regional da carcaça, de acordo com a época de nascimento

\begin{tabular}{lcrrc}
\hline \multirow{2}{*}{ Componente regional } & \multicolumn{2}{c}{ Época de nascimento } & \multirow{2}{*}{$\mathrm{P}$} \\
\cline { 3 - 4 } & & \multicolumn{1}{c}{ Agosto } & \multicolumn{1}{c}{ Novembro } & \\
\hline Paleta & $(\mathrm{kg})$ & $0,35 \pm 0,01$ & $0,29 \pm 0,01$ & $* * *$ \\
& $(\%)$ & $22,12 \pm 0,49$ & $21,32 \pm 0,46$ & $\mathrm{~ns}$ \\
Perna & $(\mathrm{kg})$ & $0,55 \pm 0,01$ & $0,45 \pm 0,01$ & $* * *$ \\
& $(\%)$ & $21,46 \pm 0,39$ & $19,35 \pm 0,37$ & $* * *$ \\
Costelas & $(\mathrm{kg})$ & $0,09 \pm 0,01$ & $0,11 \pm 0,01$ & $\mathrm{~ns}$ \\
verdadeiras & $(\%)$ & $18,92 \pm 0,65$ & $19,59 \pm 0,61$ & $\mathrm{~ns}$ \\
Costelas falsas & $(\mathrm{kg})$ & $0,16 \pm 0,01$ & $0,15 \pm 0,01$ & $\mathrm{~ns}$ \\
& $(\%)$ & $19,27 \pm 0,74$ & $19,59 \pm 0,69$ & $\mathrm{~ns}$ \\
Peito & $(\mathrm{kg})$ & $0,08 \pm 0,00$ & $0,04 \pm 0,00$ & $* * *$ \\
& $(\%)$ & $12,43 \pm 0,58$ & $9,95 \pm 0,55$ & $* *$ \\
\hline
\end{tabular}

ns $=$ Não-significativo a $5 \%$ pelo teste DMS de Fischer. $*=\mathrm{P}<0,05 \quad * *=\mathrm{P}<0,01 \quad * * *=\mathrm{P}<0,001$ 
Tabela 4 - Tecido muscular ( $\mathrm{kg} \mathrm{e} \mathrm{\% ),} \mathrm{para} \mathrm{cada} \mathrm{componente}$ regional da carcaça, de acordo com a época de nascimento

\begin{tabular}{lcrrc}
\hline Componente regional & \multicolumn{2}{c}{ Época de nascimento } & \multirow{2}{*}{$\mathrm{P}$} \\
\cline { 3 - 4 } & & \multicolumn{1}{c}{ Agosto } & \multicolumn{1}{c}{ Novembro } & \\
\hline Paleta & $(\mathrm{kg})$ & $0,80 \pm 0,03$ & $0,75 \pm 0,03$ & $\mathrm{~ns}$ \\
& $(\%)$ & $49,85 \pm 0,68$ & $55,59 \pm 0,64$ & $* * *$ \\
Perna & $(\mathrm{kg})$ & $1,51 \pm 0,05$ & $1,44 \pm 0,05$ & $\mathrm{~ns}$ \\
& $(\%)$ & $58,02 \pm 0,56$ & $61,31 \pm 0,53$ & $* * *$ \\
Costelas & $(\mathrm{kg})$ & $0,23 \pm 0,01$ & $0,26 \pm 0,01$ & $*$ \\
verdadeiras & $(\%)$ & $51,18 \pm 1,18$ & $48,66 \pm 1,11$ & $\mathrm{~ns}$ \\
Costelas falsas & $(\mathrm{kg})$ & $0,40 \pm 0,02$ & $0,37 \pm 0,02$ & $\mathrm{~ns}$ \\
& $(\%)$ & $47,22 \pm 1,12$ & $48,96 \pm 1,04$ & $\mathrm{~ns}$ \\
Peito & $(\mathrm{kg})$ & $0,25 \pm 0,01$ & $0,15 \pm 0,01$ & $* * *$ \\
& $(\%)$ & $37,44 \pm 1,13$ & $39,14 \pm 1,07$ & $\mathrm{~ns}$ \\
\hline
\end{tabular}

ns = Não-significativo a $5 \%$ pelo teste DMS de Fischer

* $=\mathrm{P}<0,05 \quad * *=\mathrm{P}<0,01 \quad * * *=\mathrm{P}<0,001$

na paleta e perna e maior peso de peito. Nos demais cortes da carcaça, não foi verificada diferença entre as épocas de nascimentos para o tecido muscular (Tabela 4).

Roque et al. (1999), Costa et al. (1999) e Osório et al. (2000) encontraram valores próximos para músculo da paleta em cordeiros Texel. Pilar et al. (2005), em cordeiros Merino e Merino x Ile de France, abatidos com 35 kg de peso corporal, observaram pesos superiores para músculo da paleta, porém, em percentuais, valores inferiores. A mesma tendência foi verificada para músculo da perna (em kg). Ribeiro et al. (2001) verificaram valores superiores para músculo da paleta, em kg, salientando que esses autores trabalharam com animais mais velhos, com idade média de 12 meses, das raças Ile de France e Hampshire Down.

A condição corporal é uma medida subjetiva que indica o estado de engorduramento da carcaça (Osório \& Osório, 2005). Entretanto, neste estudo, embora não tenha havido diferenças entre as épocas de nascimento para esse parâmetro, os cordeiros nascidos em novembro apresentaram carcaças menos engorduradas (Mendonça et al., 2007), o que pode ter sido responsável pela maior proporção de músculo na paleta e perna nos cordeiros nascidos nessa época comparativamente aos nascidos em agosto.

Rodrigues et al. (2006) verificaram que o percentual de músculo permaneceu relativamente constante com o incremento no grau de maturidade em cordeiros das raças Suffolk e Churra Galega Bragançana. Roque et al. (1999) registraram diminuição na proporção de músculo da paleta com o incremento no peso desse corte, em cordeiros da raça Texel. Osório et al. (2000) encontraram diminuição no percentual de músculo da perna em cordeiros Texel, com o aumento na idade de abate.
Nos cordeiros nascidos em agosto, em kg, verificaram-se maiores valores em todos os tipos de gordura $(\mathrm{P}<0,05)$, exceto na gordura total das costelas verdadeiras e na intermuscular das costelas falsas, não sendo observadas diferenças $(\mathrm{P}>0,05)$. Em percentuais, os cordeiros da primeira época foram superiores para a mesma variável em relação aos nascidos em novembro $(\mathrm{P}<0,05)$, exceto na gordura intermuscular do peito e das costelas falsas, bem como na gordura total do peito $(\mathrm{P}>0,05)$ (Tabelas 5 e 6$)$.

Portanto, os cordeiros nascidos em agosto tiveram maior conteúdo de gordura na maioria dos cortes da carcaça, o que denota melhores condições nutricionais durante as fases de crescimento e desenvolvimento, uma vez que esses cordeiros tiveram também superior estado de engorduramento da carcaça e espessura da gordura de cobertura (Mendonça et al., 2007). O sistema de alimentação influencia a composição tecidual dos cordeiros. Condições nutricionais superiores às oferecidas pelo campo nativo possibilitam a obtenção de carcaças com adequada quantidade e distribuição de gordura, em menor espaço de tempo (Osório et al., 2002b).

Neste estudo os cordeiros nascidos em agosto tiveram maior peso de carcaça quente e fria, determinado principalmente pela maior deposição de tecido adiposo (Mendonça et al., 2007). Este resultado corrobora inferências de Bonagurio et al. (2003), de que carcaças mais pesadas apresentam maior quantidade de gordura de cobertura, e de Osório et al. (2002b), de que a quantidade de gordura eleva-se com o aumento do peso de carcaça, estando a quantidade

Tabela 5 - Tecido adiposo ( $\mathrm{kg}$ e \%), na paleta e na perna, de acordo com a época de nascimento

\begin{tabular}{lcccc}
\hline Componente regional & & Época de nascimento & P \\
\cline { 2 - 4 } & & Agosto & Novembro & \\
\hline Paleta & & & & \\
Gordura & $\mathrm{kg}$ & $0,09 \pm 0,01$ & $0,06 \pm 0,01$ & $* *$ \\
intermuscular & $\%$ & $5,5 \pm 0,4$ & $4,4 \pm 0,4$ & $*$ \\
Gordura subcutânea & $\mathrm{kg}$ & $0,22 \pm 0,02$ & $0,11 \pm 0,01$ & $* * *$ \\
& $\%$ & $13,1 \pm 0,7$ & $8,3 \pm 0,7$ & $* * *$ \\
Gordura total & $\mathrm{kg}$ & $0,30 \pm 0,02$ & $0,17 \pm 0,02$ & $* * *$ \\
& $\%$ & $18,6 \pm 0,8$ & $12,7 \pm 0,7$ & $* * *$ \\
\hline Perna & & & & \\
Gordura intermuscular & $\mathrm{kg}$ & $0,13 \pm 0,01$ & $0,08 \pm 0,01$ & $* * *$ \\
& $\%$ & $5,1 \pm 0,3$ & $3,4 \pm 0,3$ & $* * *$ \\
Gordura subcutânea & $\mathrm{kg}$ & $0,20 \pm 0,02$ & $0,10 \pm 0,02$ & $* * *$ \\
& $\%$ & $7,5 \pm 0,5$ & $4,0 \pm 0,5$ & $* * *$ \\
Gordura total & $\mathrm{kg}$ & $0,34 \pm 0,02$ & $0,17 \pm 0,02$ & $* * *$ \\
& $\%$ & $12,6 \pm 0,6$ & $7,3 \pm 0,6$ & $* * *$ \\
\hline
\end{tabular}

ns $=$ Não-significativo a $5 \%$ pelo teste DMS de Fischer

$*=\mathrm{P}<0,05 \quad * *=\mathrm{P}<0,01 \quad * * *=\mathrm{P}<0,001$ 
de gordura estreitamente relacionada aos pesos corporal e de carcaça.

Osório et al. (2002a) verificaram valores semelhantes aos deste trabalho para gordura subcutânea (\%) na paleta e superiores para gordura intermuscular $(\mathrm{kg})$ na paleta e perna. Pilar et al. (2005) encontraram valores semelhantes para gordura total da paleta (\%), em cordeiros Merino e Merino × Ile de France. Talvez, as diferenças decorram dos genótipos utilizados.

A gordura é o componente que apresenta maior variação em função do nível nutricional (Alves et al., 2003). De acordo com Sañudo et al. (1997), as diferenças mais importantes entre componentes dissecáveis são verificadas para proporção de gordura, sugerindo a existência de variabilidade entre raças para partição e distribuição da gordura através do corpo.

Verificou-se que os cordeiros nascidos em novembro tiveram maiores relações músculo:gordura e músculo:osso na paleta e na perna que os nascidos em agosto. Nos demais cortes da carcaça, não houve diferença significativa entre as épocas de nascimento para nenhuma das relações (Tabela 7).

Pilar et al. (2005) observaram valores inferiores aos deste estudo para músculo:gordura e superiores para músculo:osso na perna, em cordeiros Merino e Merino × Ile de France. Já para as mesmas relações na paleta, esses autores verificaram valores superiores e inferiores para músculo:osso e músculo:gordura, respectivamente.

Tabela 6 - Tecido adiposo ( $\mathrm{kg}$ e \%), no peito, nas costelas verdadeiras e costelas falsas, de acordo com a época de nascimento

\begin{tabular}{lcccc}
\hline \multirow{2}{*}{ Componente regional } & & \multicolumn{2}{c}{ Época de nascimento } & \multirow{2}{*}{$\mathrm{P}$} \\
\cline { 3 - 4 } & & Agosto & Novembro & \\
\hline Peito & & & & \\
Gordura intermuscular & $\mathrm{kg}$ & $0,10 \pm 0,01$ & $0,06 \pm 0,01$ & $* *$ \\
& $\%$ & $14,2 \pm 1,0$ & $15,9 \pm 1,0$ & $\mathrm{~ns}$ \\
Gordura subcutânea & $\mathrm{kg}$ & $0,09 \pm 0,01$ & $0,03 \pm 0,01$ & $* * *$ \\
& $\%$ & $13,3 \pm 1,5$ & $8,2 \pm 1,5$ & $*$ \\
Gordura total & $\mathrm{kg}$ & $0,18 \pm 0,01$ & $0,10 \pm 0,01$ & $* * *$ \\
& $\%$ & $27,5 \pm 1,6$ & $24,1 \pm 1,6$ & $\mathrm{~ns}$ \\
\hline Costelas verdadeiras & & & & \\
Gordura total & $\mathrm{kg}$ & $0,06 \pm 0,01$ & $0,05 \pm 0,01$ & $\mathrm{~ns}$ \\
& $\%$ & $13,2 \pm 1,0$ & $8,9 \pm 0,9$ & $* *$ \\
\hline Costelas falsas & & & & \\
Gordura intermuscular & $\mathrm{kg}$ & $0,07 \pm 0,01$ & $0,07 \pm 0,01$ & $\mathrm{~ns}$ \\
& $\%$ & $8,3 \pm 0,9$ & $8,9 \pm 0,9$ & $\mathrm{~ns}$ \\
Gordura subcutânea & $\mathrm{kg}$ & $0,10 \pm 0,01$ & $0,05 \pm 0,02$ & $*$ \\
& $\%$ & $11,1 \pm 1,2$ & $6,2 \pm 1,5$ & $*$ \\
Gordura total & $\mathrm{kg}$ & $0,17 \pm 0,02$ & $0,09 \pm 0,02$ & $* *$ \\
& $\%$ & $18,9 \pm 1,6$ & $11,6 \pm 1,5$ & $* *$ \\
\hline
\end{tabular}

ns = Não-significativo a $5 \%$ pelo teste DMS de Fischer.

$*=\mathrm{P}<0,05 \quad * *=\mathrm{P}<0,01 \quad * * *=\mathrm{P}<0,001$
Estes resultados reforçam os descritos anteriormente, segundo os quais houve maior proporção de tecido muscular, principalmente na paleta e na perna, para os cordeiros nascidos em novembro. Os cordeiros nascidos nessa época apresentaram, ainda, menores engorduramento da carcaça, espessura da gordura de cobertura e conteúdo de gordura subcutânea, intermuscular e total (Mendonça et al., 2007). Certamente, a deficiência nutricional sofrida por esses cordeiros foi o fator responsável pelas diferenças encontradas e, caso houvesse suplementação alimentar para esses animais, seriam minimizadas as desigualdades entre as épocas de nascimento.

Tabela 7 - Relações músculo:osso e músculo:gordura nas regiões da carcaça, de acordo com a época de nascimento

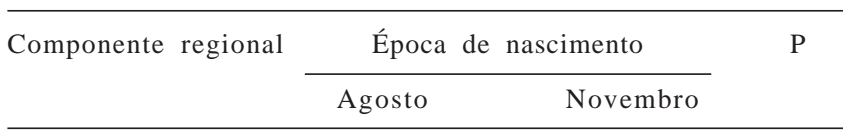

Paleta

$\begin{array}{llll}\text { Músculo:osso } & 2,18 \pm 0,10 & 2,58 \pm 0,07 & * * \\ \text { Músculo:gordura } & 3,34 \pm 0,37 & 4,92 \pm 0,28\end{array}$ **

Músculo:gordura

$3,34 \pm 0,37$

$4,92 \pm 0,28 \quad * *$

Perna

$\begin{array}{lccc}\text { Músculo:osso } & 2,62 \pm 0,09 & 3,16 \pm 0,06 & * * * \\ \text { Músculo:gordura } & 5,47 \pm 1,60 & 10,96 \pm 1,30 & *\end{array}$

Peito

Músculo:osso

Músculo:gordura

$3,24 \pm 0,35$

$4,01 \pm 0,26$

ns

Costelas falsas

Músculo:osso

$1,90 \pm 0,17$

$1,73 \pm 0,14$

ns

Músculo:gordura

$2,41 \pm 0,18$

$2,62 \pm 0,13$

$7,50 \pm 1,74$

ns

ns = Não-significativo a $5 \%$ pelo teste DMS de Fischer.

* $=\mathrm{P}<0,05 \quad$ ** $=\mathrm{P}<0,01 \quad$ *** $=\mathrm{P}<0,001$

Tabela 8 - Outros tecidos ( $\mathrm{kg}$ e \%), nas regiões da carcaça, de acordo com a época de nascimento

\begin{tabular}{lcrrc}
\hline Componente regional & \multicolumn{2}{c}{ Época de nascimento } & \multirow{2}{*}{ P } \\
\cline { 2 - 4 } & & \multicolumn{1}{c}{ Agosto } & \multicolumn{1}{c}{ Novembro } & \\
\hline Paleta & $\mathrm{kg}$ & $0,15 \pm 0,01$ & $0,14 \pm 0,01$ & $\mathrm{~ns}$ \\
& $\%$ & $9,44 \pm 0,41$ & $10,44 \pm 0,39$ & $\mathrm{~ns}$ \\
Perna & $\mathrm{kg}$ & $0,21 \pm 0,01$ & $0,29 \pm 0,01$ & $* * *$ \\
& $\%$ & $7,93 \pm 0,32$ & $12,30 \pm 0,30$ & $* * *$ \\
Peito & $\mathrm{kg}$ & $0,15 \pm 0,01$ & $0,11 \pm 0,01$ & $* * *$ \\
& $\%$ & $22,64 \pm 1,24$ & $27,78 \pm 1,17$ & $* *$ \\
Costelas verdadeiras & $\mathrm{kg}$ & $0,08 \pm 0,01$ & $0,13 \pm 0,01$ & $* * *$ \\
& $\%$ & $16,73 \pm 0,89$ & $22,84 \pm 0,83$ & $* * *$ \\
Costelas falsas & $\mathrm{kg}$ & $0,13 \pm 0,01$ & $0,15 \pm 0,01$ & $*$ \\
& $\%$ & $14,61 \pm 0,91$ & $20,34 \pm 0,85$ & $* * *$ \\
\hline
\end{tabular}

ns $=$ Não-significativo a $5 \%$ pelo teste DMS de Fischer.

* $=\mathrm{P}<0,05 \quad * *=\mathrm{P}<0,01 \quad * * *=\mathrm{P}<0,001$ 
Os cordeiros nascidos em agosto apresentaram menor conteúdo de tecidos considerados "outros" na perna, no peito, nas costelas verdadeiras e nas costelas falsas (\%), ainda em valores absolutos na perna, nas costelas verdadeiras e nas costelas falsas. No peito foi verificado maior conteúdo deste tecido em valores absolutos (Tabela 8).

Os valores obtidos foram superiores, tanto em $\mathrm{kg}$ quanto em \%, aos verificados por Osório et al. (2002a), em cordeiros cruzas Border Leicester $\times$ Ideal e Border Leicester $\times$ Corriedale. A menor quantidade desse tecido encontrada nos cordeiros nascidos em agosto deve-se ao maior desenvolvimento dos demais tecidos (ósseo, muscular e adiposo), assim à menor idade desses animais.

\section{Conclusões}

O uso de uma época alternativa de nascimentos para incrementar a oferta de cordeiros para o abate é viável em regime de pasto, recomendando-se o monitoramento e a padronização das condições nutricionais para evitar diferenças no volume e proporção de cortes, assim como na composição tecidual da carcaça.

\section{Literatura Citada}

ALVES, K.S.; CARVALHO, F.F.R.; FERREIRA, M.A. et al. Níveis de energia em dietas para ovinos Sant Inês: características de carcaça e constituintes corporais. Revista Brasileira de Zootecnia, v.32, n.6, p.1927-1936, 2003 (supl. 2).

BONAGURIO, S.; PÉREZ, J.R.O.; FURUSHO GARCIA, I.F. et al. Qualidade da carne de cordeiros Santa Inês puros e mestiços com Texel abatidos com diferentes pesos. Revista Brasileira de Zootecnia, v.32, n.6, p.1981-1991, 2003 (supl. 2).

CAÑEQUE, V.; HUIDOBRO, F.R.; DOLZ, J.F. et al. Producción de carne de cordero. Zaragoza: Ministerio de Agricultura Pesca y Alimentación, 1989. 520p.

CANO EXPÓSITO, T.; PEÑA BLANCO, F.; MARTOS PEINADO, J. et al. Calidad de la canal y de la carne en corderos ligeros de raza Segureña. Archivos de Zootecnia, v.52, p.315-326, 2003.

COSTA, J.C.C.; OSÓRIO, J.C.S.; OSÓRIO, M.T.M. et al. Composição regional e tecidual em cordeiros não castrados. Revista Brasileira de Agrociência, v.5, n.1, p.50-53, 1999.

FRESCURA, R.B.M.; PIRES, C.C.; SILVA, J.H.S. et al. Avaliação das proporções dos cortes da carcaça, características da carne e avaliação dos componentes do peso vivo de cordeiros. Revista Brasileira de Zootecnia, v.34, n.1, p.167-174, 2005.

GARIBOTTO, G.; BIANCHI, G.; OLIVEIRA, G. et al. Cruzamientos terminales sobre ovejas Corriedale en el Uruguay, 2. Peso, composición y calidad de canales en corderos sacrificados a los 145 días de edad. Información Técnica Económica Agraria - ITEA, v.95A, n.3, p.248-258, 1999.

GOLIOMYTIS, M.; ORFANOS, S.; PANOPOULOU, E. et al. Growth curves for body weight and carcass components, and carcass composition of the Karagouniko sheep, from birth to 720 d of age. Small Ruminant Research, v.66, n.1-3, p.222-229, 2006.

GUTIÉRREZ, J.; RUBIO, M.S.; MÉNDEZ, R.D. Effects of crossbreeding Mexican Pelibuey sheep with Rambouillet and Suffolk on carcass traits. Meat Science, v.70, p.1-5, 2005.
MENDONÇA, G.; OSÓRIO, J.C.S.; OSÓRIO, M.T.M. et al. Avaliação da época de nascimento sobre o desenvolvimento corporal e os rendimentos pós-abate de cordeiros da raça Texel. Revista Brasileira de Zootecnia, v.36, n.4, p.1119-1125, 2007 (supl.).

MOHRDIECK, K.H. Formações campestres do Rio Grande do Sul. In: FEDERACITE - Campo Nativo, Melhoramento e Manejo, 4., 1993, Porto Alegre. Palestras... Porto Alegre: FEDERACITE, 1993. 108p.

OSÓRIO, J.C.; OLIVEIRA, N.M.; OSÓRIO, M.T. et al. Efecto de la edad al sacrificio sobre la producción de carne en corderos no castrados de cuatro razas. Revista Brasileira de Agrociência, v.6, n.2, p.161-166, 2000.

OSÓRIO, J.C.S.; OLIVEIRA, N.M.; OSÓRIO, M.T.M. et al. Produção de carne em cordeiros cruza Border Leicester com ovelhas Corriedale e Ideal. Revista Brasileira de Zootecnia, v.31, n.3, p.1469-1480, 2002a (supl.).

OSÓRIO, J.C.S.; OSÓRIO, M.T.M. Produção de carne ovina: Técnicas de avaliação in vivo e na carcaça. 2.ed. Pelotas: Universidade Federal de Pelotas, 2005. 82p.

OSÓRIO, J.C.S.; OSÓRIO, M.T.M.; OLIVEIRA, N.M. et al. Qualidade, morfologia e avaliação de carcaças. Pelotas: Universidade Federal de Pelotas, 2002b. 194p.

PILAR, R.C.; PÉREZ, J.R.O.; NUNES, F.M. Rendimento e caracteres quantitativos de carcaça em cordeiros Merino Australiano e cruza Ile de France x Merino Australiano. Revista Brasileira de Agrociência, v.11, n.3, p.351-359, 2005.

PURCHAS, R.W.; SILVA SOBRINHO, A.G.; GARRICK, D.J. et al. Effects of age at slaughter and sire genotype on fatness, muscularity, and the quality of meat from ram lambs born to Romney ewes. New Zealand Journal of Agricultural Research, v.45, p.77-86, 2002.

RIBEIRO, E.L.A.; ROCHA, M.A.; MIZUBUTI, I.Y. et al. Carcaça de borregos Ile de France inteiros ou castrados e Hampshire Down castrados abatidos aos doze meses de idade. Ciência Rural, v.31, n.3, p.479-482, 2001.

RODRIGUES, S.; CADAVEZ, V.; TEIXEIRA, A. Breed and maturity effects on Churra Galega Bragançana and Suffolk lamb carcass characteristics: killing-out proportion and composition. Meat Science, v.72, p.288-293, 2006.

ROQUE, A.P.; OSÓRIO, J.C.S.; JARDIM, P.O. et al. Produção de carne em ovinos de cinco genótipos. 6. Desenvolvimento relativo. Ciência Rural, v.29, n.3, p.549-553, 1999.

SANTOS, C.L.; PÉREZ, J.R.O.; MUNIZ, J.A. et al. Desenvolvimento relativo dos tecidos ósseo, muscular e adiposo dos cortes da carcaça de cordeiros Santa Inês. Revista Brasileira de Zootecnia, v.30, n.2, p.487-492, 2001.

SAÑUDO, C.; CAMPO, M.M.; SIERRA, I. et al. Breed effect on carcass and meat quality of suckling lambs. Meat Science, v.46, n.4, p.357-365, 1997.

STATISTICAL ANALYSIS SYSTEM - SAS. SAS Technical Report. Release 8.01 TS Level 01MO. Cary: SAS Institute, 2001. (CD-ROM).

SILVA SOBRINHO, A.G. Body composition and characteristics of carcasses from lamb of different genotypes and ages at slaughter. Palmerston North: Massey University, 1999. 54p (Post Doctoral Research Report).

SILVA SOBRINHO, A.G.; SILVA, A.M.A. Produção de carne ovina. Revista Nacional da Carne, v.24, n.285, p.32-44, 2000.

TONETTO, C.J.; PIRES, C.C.; MÜLLER, L. et al. Rendimentos de cortes da carcaça, características da carne e componentes do peso vivo em cordeiros terminados em três sistemas de alimentação. Revista Brasileira de Zootecnia, v.33, n.1, p.234-241, 2004.

TOTHILL, J.C.; HARGRAVES, J.N.G.; JONES, R.M. et al. BONTANAL - a comprehensive sampling and computing procedure for estimating pasture yield and composition. 1. Field sampling. Tropical Agronomy Technical Memorandum, v.78, p.9-15, 1992. 